\title{
Seminal Fluid
}

National Cancer Institute

\section{Source}

National Cancer Institute. Seminal Fluid. NCI Thesaurus. Code C33529.

Part of the ejaculated fluid. It contains secretions from the seminal vesicles, Cowper's gland, and prostate gland. 